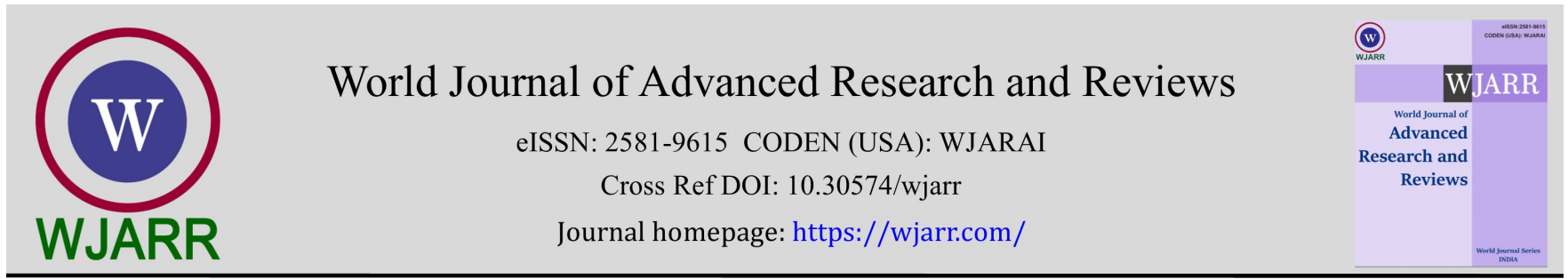

(RESEARCH ARTiClE)

Check for updates

\title{
Echographic study of the variation in endometry thickness in women 15 to 40 years old in Lokossa district in Benin
}

\author{
Gbaguidi Ahotondji Bertin 1, ${ }^{*}$, Avocefohoun Sako Alphonse 1, 2, Komabou Fulbert 1, Youssao Abdou Karim \\ Alassane ${ }^{2}$, Gbaguidi Nonvignon Magloire ${ }^{2}$, Ayi Virgile ${ }^{5}$, Biaou Olivier ${ }^{3}$ and Baba-Moussa Lamine Said ${ }^{4}$
}

${ }^{1}$ Applied Biology Research Laboratory (LARBA) at the Polytechnic school of Abomey-Calavi (UAC).

${ }^{2}$ Laboratory of Study and Research in Applied Chemistry (LERCA).

${ }^{3}$ Faculty of Health Sciences, University of Abomey-Calavi, Benin.

${ }^{4}$ Laboratory of Biology and Molecular Typing in Microbiology.

${ }^{5}$ Regional Institute of Industrial Engineering and Biotechnologies (IRGIB).

World Journal of Advanced Research and Reviews, 2021, 12(02), 500-509

Publication history: Received on 19 October 2021; revised on 22 November 2021; accepted on 24 November 2021

Article DOI: https://doi.org/10.30574/wjarr.2021.12.2.0639

\begin{abstract}
The endometrium is a deep, basal, very thin layer lining the uterine cavity that changes during the menstrual cycle. The present work is a contribution to assess the thickness of the endometrium according to the period of the menstrual cycle in women aged 15 to 40 years. This is a descriptive and prospective cross-sectional study involving 166 women aged 15 to 40 years in Lokossa. Ultrasound examination measured the thickness of the endometrium on the longitudinal section through the suprapubic route. Anthropometric parameters were taken by other equipment in each woman. At the end of the study, the minimum, average and maximum values of the thickness of the endometrium obtained are respectively $\mathrm{Vm}=3.50 \mathrm{~mm}, \mathrm{VMoy}=6.73 \pm 1.38 \mathrm{~mm}, \mathrm{MV}=10.00 \mathrm{~mm}$ during the pre-ovulatory phase, $\mathrm{Vm}=7.30 \mathrm{~mm}$, VMoy $=10.75 \pm 2.11 \mathrm{~mm}, \mathrm{MV}=16.00 \mathrm{~mm}$ during the post-ovulatory period. There is a link of association between the thickness of the endometrium and the phases of the cycle $(P=0.0000)$, but the test is statistically significant between the thickness and the age groups and the Mass Index Body (BMI). This allows us to say that the thickness of the endometrium normally varies with the phases of the menstrual cycle and with age.
\end{abstract}

Keywords: Ultrasound; Endometrial thickness; Menstrual cycle; Mono Departmental Hospital Center; Benin

\section{Introduction}

The endometrium is a deep, basal, very thin layer that lines the uterine cavity. It undergoes morphological and physiological changes in women of childbearing age. This is linked, among other things, to the presence of estrogen receptors in it, which puts it under the control of reproductive hormones [1] The assessment of the thickness of the endometrium is used as a biological marker of good regulation of the secretion of reproductive hormones [2]. Some authors have noticed a low pregnancy rate in women with a thin endometrium. The thickness of the endometrium is also an important parameter which is taken into account in the process of artificial insemination [3]; [4].

In fact, ultrasound, the first-line examination in exploring the internal genital organs in women, makes it possible to study the variation in its thickness, its echogenicity, its regularity and its pathologies [5]. With regard to the capital role of the endometrium, a few authors have focused on its variation, depending on race [1]. The estimation of normal values for endometrial thickness on ultrasound has also been the subject of some work. For this objective [6] in a study on an American population had found an average value of 6 to $12 \mathrm{~mm}$, these same values were confirmed by [2], [6].

\footnotetext{
${ }^{*}$ Corresponding author: Gbaguidi Ahotondji Bertin

Applied Biology Research Laboratory (LARBA) at the Polytechnic school of Abomey-Calavi (UAC).

Copyright $(2021$ Author(s) retain the copyright of this article. This article is published under the terms of the Creative Commons Attribution Liscense 4.0.
} 
Knowledge of normal endometrial values is an important part of exploring endometrial conditions in a woman's reproductive life.

\section{Framework, material and study methods}

\subsection{Study framework}

The present study took place at the Departmental Hospital Center of Mono (CHD / Mono) in the Municipality of Lokossa. The municipality of Lokossa has a total of five districts which are Lokossa, Agamè, Koudo, Houin and Ouèdèmè-Adja. It is bounded to the north by the municipality of Dogbo in Couffo, to the south by the municipalities of Athiémé and Houéyogbé, to the east by that of Bopa and to the west by the Togolese territory (figure 1).

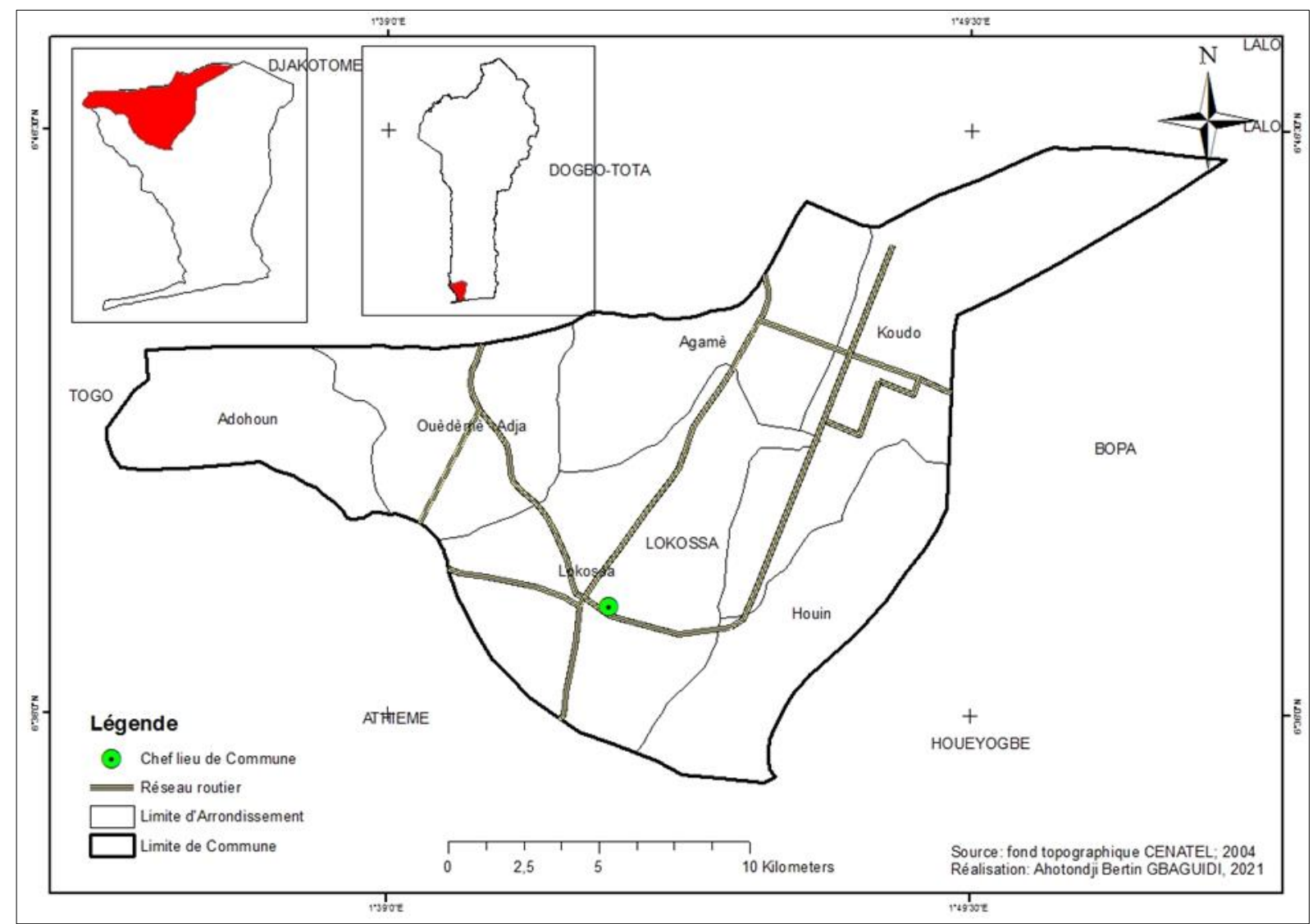

Figure 1 Geographical location of the Municipality of Lokossa

It covers an area of $260 \mathrm{~km} 2$ which represents $16 \%$ of the Mono area. According to the 2013 census, it has 104,961 inhabitants with $51.14 \%$ of women.

The Departmental Hospital Center of Mono (CHD-M) is a referral hospital. This is a public health facility with a social character. Its initial reception capacity is one hundred and twenty (120) beds and the number of staff is 218 agents.

\subsection{Study materials and methods}

\subsubsection{Type and period of study}

This is a cross-sectional, descriptive and prospective study that took place within the Departmental Hospital Center of Mono (CHD-M). 


\subsubsection{Study population}

The study population includes women aged 15 to 40 regardless of the menstrual cycle and who attend the CHD-Mono maternity ward and those who come for a ginechological ultrasound examination in the medical imaging department of this hospital. A total of 166 women took part in this study.

\subsubsection{Data collection materials and tools}

The data collection material consists of:

a MINDRAY DC-6 brand ultrasound system equipped with four probes: (3.5 MHz sector probe; $7.4 \mathrm{MHz}$ linear probe, 6.1 $\mathrm{MHz}$ endovaginal probe; $2.2 \mathrm{MHz}$ cardiac probe). In the present study, the $3.5 \mathrm{MHz}$ sector probe was used for the examinations.

- A Sony reprographer to print the images.

- Thermal paper.

- coupling gel;

- towels for patient hygiene;

- An investigation sheet.

Data collection technique

Anthropometric data was collected from care logs or directly by questionnaire (ages) and the other by taking weight and height measurements. Morphological data were collected from measurements taken during gynecological ultrasound examinations. Finally, the body mass index (BMI) of the different women was calculated by the formula BMI $=$ weight $(\mathrm{kg}) /$ height $^{2}\left(\mathrm{M}^{2}\right)$

The WHO BMI table was used as a reference to assess the excess weight of the women surveyed:

- $\quad$ normal weight: if BMI between 18.5 and 24.9

- $\quad$ overweight: if BMI between 25 and 29.9

- Obesity class I: if BMI between 30 and 34.9

- Obesity class II (severe): if BMI between 35.0 and 39.9

- Class III obesity (massive): BMI greater than 40

Longitudinal pelvic ultrasound was the technique adopted.

From the images from the gynecological ultrasound, the following measurements were taken using an electronic marker:

- the length of the uterus, which is the distance between the midpoint of the outer wall of the fundus and the cervix;

- the anteroposterior thickness or widest diameter of the uterus which is the largest axis connecting the anterior outer wall and the posterior outer wall of the uterus. This axis is perpendicular to the previous one;

- The thickness of the endometrium is made on the sagittal section perpendicular to the cavity line between the two layers of the endometrium. When the cavity is distended by liquid, the thickness of each sheet measured separately is added (Richard J., n.d.);

To avoid inter-observer differences, all uterine measurements were performed on the same device by a single investigator.

\section{Statistical data processing}

The data collected were entered into Microsoft Excel 2007 and then entered into the R 4.0.2 software which was used to calculate the means, maximum and minimum values, standard deviations, confidence intervals for the thickness of the endometrium. , the correlation coefficients between the thickness of the endometrium, age, weight, height, Body Mass Index.

Linear regression was used to perform the correlation test. This test is used to study the link between two quantitative variables. The correlation coefficient varies between -1 (negative correlation) and 1 (positive correlation). 
We admit that the coefficient of positive correlation satisfies the relation:

I $\mathrm{r} I<1$

If $-1<\mathrm{r}<0$ then the correlation is negative;

If $0<\mathrm{r} 1$ then the correlation is positive;

If $r=0$, the relation is zero linear and independent of the parameters;

If $0<\mathrm{r} \leq 0.24$, the correlation is said to be weak or even zero;

If $0.25<r \leq 0.49$, the relation is mean;

If $0.5<\mathrm{r} \leq 0.74$ ], there is a good correlation between the two parameters considered;

When $0.75<\mathrm{r} \leq 1$, the correlation is excellent.

\subsection{Comparison test}

The comparison of the means was carried out from the student test. This comparison test allows you to know if there is a statistically significant difference between the means of two or more samples. Thus, the difference is significant if the value of $\mathrm{p}$ (error threshold of the first kind) is less than or equal to $0.05(\mathrm{p} \leq 0.05)$ at the $5 \%$ threshold.

\section{Results}

\subsection{Characteristics of the study population}

The present study looked at the length and regularity of the menstrual cycle in the women surveyed. The results for the length of periods are shown in Figure 2.

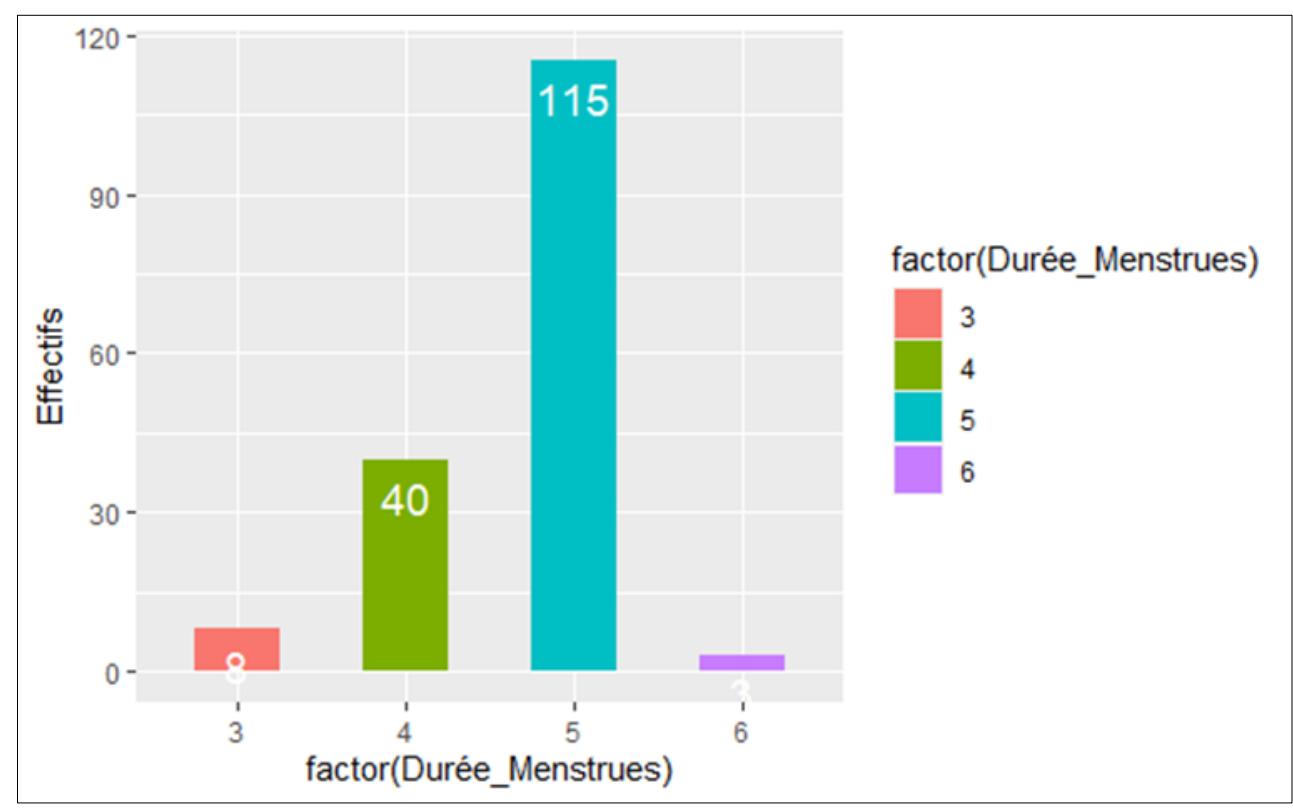

Figure 2 Distribution of women according to the length of their periods; (Source: Fieldwork, Komahoue, 2019)

As shown in Figure 2, the duration of menstruation is 5 days in $69.28 \%$ of the women surveyed, 4 days in $24.09 \%$. The rest of the women have 3 days and 6 days.

Table 1 Distribution of women according to cycle regularity

\begin{tabular}{l|c|c|}
\hline \multicolumn{1}{c}{ CYCLE TYPE } & EFF & FREQUENCES \\
\hline Regular & 133 & 79.51 \\
\hline Irregular & 33 & 20.49 \\
\hline TOTAL & 166 & 100.00 \\
\hline \multicolumn{2}{c}{ Source: Fieldwork, Komahoue, 2019} \\
\hline
\end{tabular}


Regarding the regularity of cycles, Table I shows the distribution of women surveyed according to the regularity of the menstrual cycle.

It emerges from the analysis of Table I that the majority or $79.51 \%$ of respondents have a regulated cycle and $20.49 \%$ have irregular cycles.

\subsection{Anthropometric parameters}

The anthropometric parameters of women were entered as part of the present study in order to investigate their correlations with variations in the thickness of the endometrium. The results of the field surveys are shown in Table II.

Table 2 Anthropometric parameters of the women in the study

\begin{tabular}{lccc|}
\hline Anthropometries' Parameters & Min & Moy $\pm \boldsymbol{\sigma}$ & \multicolumn{1}{c}{ Max } \\
\hline Age (ans) & 17.00 & $30.00 \pm 6.94$ & 41.00 \\
\hline Size (m) & 01.40 & $01.65 \pm 0.08$ & 01.78 \\
\hline Weight (Kg) & 52.00 & $68.21 \pm 7.73$ & 645.00 \\
\hline IMC & 16.23 & $25.15 \pm 3.68$ & 38.15 \\
\hline
\end{tabular}

From the analysis of Table II, it appears that the average age of the women in the study is $30.00 \pm 6.94$ years. The youngest is 17 and the oldest is 41 . The average height of the women in the study is $1.65 \mathrm{~m}$ with $1.40 \mathrm{~m}$ for the woman with the shortest height and $1.78 \mathrm{~m}$ for the slender one. The average weight obtained is $68.21 \mathrm{~kg}$, the minimum obtained is $52 \mathrm{~kg}$. Regarding the BMI the average value obtained after calculation is $25.41 \pm 3.68 \mathrm{~kg} / \mathrm{m} 2$, the smallest value is $16.23 \mathrm{~kg} / \mathrm{m} 2$ and the highest value is $35.15 \mathrm{~kg} / \mathrm{m} 2$

\subsection{Endometrial thickness of women}

The women's endometrial thickness was measured and classified according to the woman's regular or irregular cycle. Table III shows the results obtained in women with the regular cycle.

Table 3 Minimum, mean $\pm \sigma$, maximum values of the thickness of the endometrium of women with the regular cycle

\begin{tabular}{lccc|}
\hline Phases & Min & Moy $\pm \sigma$ & Max \\
\hline Pré & 3.1 & $06.76 \pm 1.80$ & 10.10 \\
\hline Post & 5.4 & $11.20 \pm 2.42$ & 17.60 \\
\hline \multicolumn{4}{|c|}{ Source: Fieldwork, Komahoue, 2019} \\
\hline
\end{tabular}

As shown in Table III, the average value of the endometrial thickness of women with a regular cycle is $6.76 \mathrm{~mm}$ before ovulation and $11.20 \mathrm{~mm}$ after ovulation. The minimum values are $3.1 \mathrm{~mm}$ before ovulation and $5.4 \mathrm{~mm}$ after ovulation. Maximum values are in the order of $10.10 \mathrm{~mm}$ and $17.60 \mathrm{~mm}$ before and after ovulation.

The results for women with irregular cycles are shown in Table IV.

Table 4 Minimum, mean $\pm \sigma$, maximum values of the thickness of the endometrium of women with the irregular cycle

\begin{tabular}{lccl|}
\hline PHASES & Min & Moy $\pm \sigma$ & Max \\
\hline Pré & 3.5 & $06.73 \pm 1.18$ & 10.00 \\
\hline Post & 7.1 & $9.72 \pm 2.11$ & 18.00 \\
\hline \multicolumn{4}{|c|}{ Source: Fieldwork, Komahoue, 2019 }
\end{tabular}

In women with irregular cycles, the results presented in Table IV show that in the pre-ovulatory phase, the mean endometrial value is $6.73 \mathrm{~mm}$, while in the post-ovulatory phase it is $9.72 \mathrm{~mm}$. The minimum values obtained are 3.5 $\mathrm{mm}$ and $7.1 \mathrm{~mm}$ respectively before ovulation and the maximum values for thicknesses are in the order of $10 \mathrm{~mm}$ and 
$18 \mathrm{~mm}$ after ovulation. Photos 1 and 2 show pelvic ultrasound images in longitudinal section in the pre-ovular phase and ovulatory post.
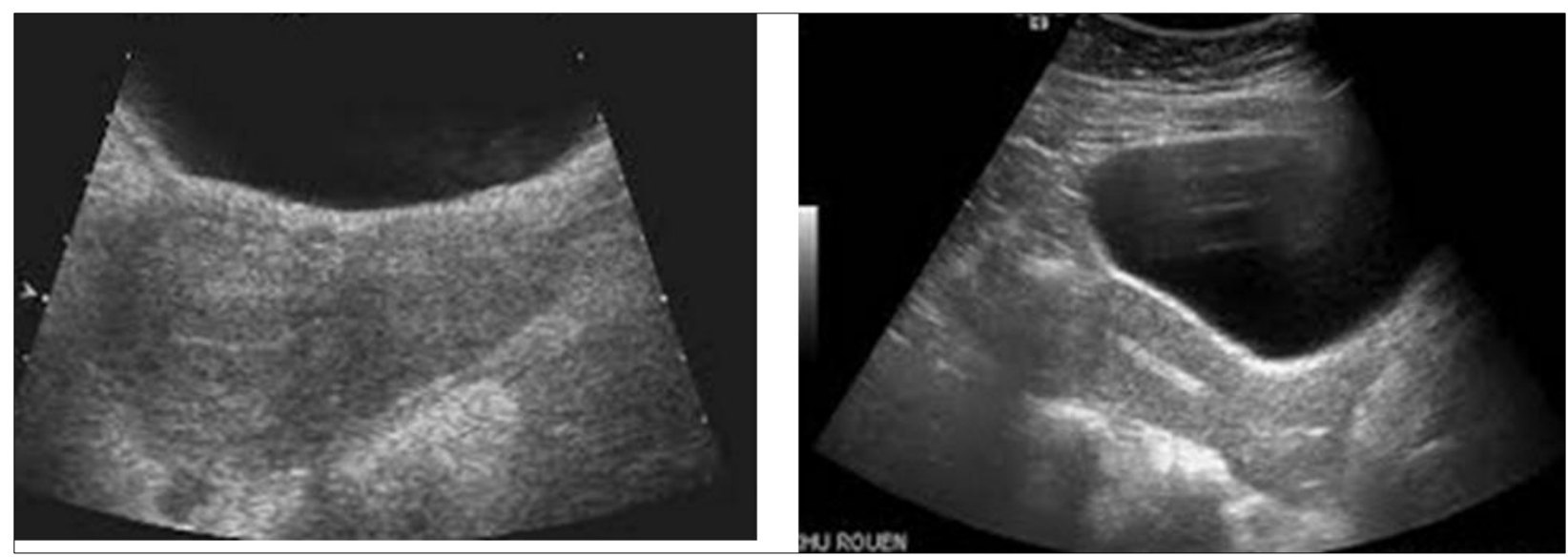

Figure 3 Pelvic ultrasound image Photo 2: Pelvic ultrasound image in longitudinal section in post-ovular phase longitudinal section in pre-ovular phase Shooting: KOMAHOUE, 2019

\subsection{Correlations between endometrial thickness and anthropometric factors in women}

In order to determine the influence of a woman's characteristics on the thickness of her endometrium, the correlation between the value of the thickness of the endometrium and the characteristics was verified. The results of this work are presented in Figures 3 and 4.

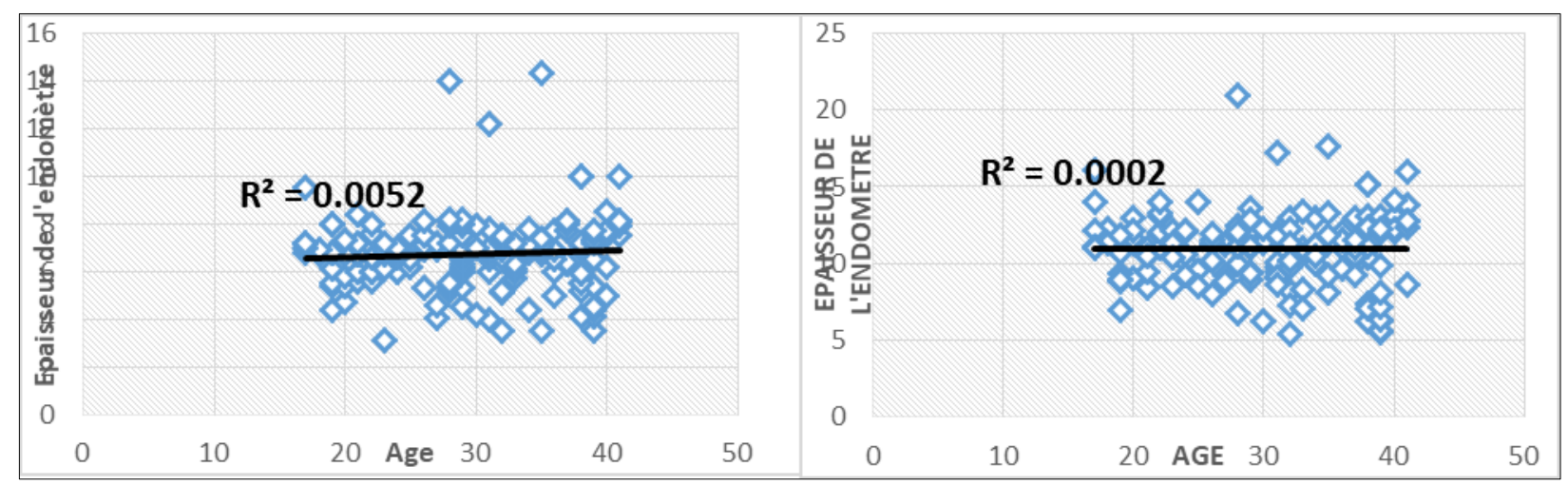

Figure 4 Endometrial thickness in phase Figure 5: Endometrial thickness in phase preovulatory as a function of postovulatory age as a function of age; (Source: Fieldwork, Komahoue, 2019)

On reading Figures 3 and 4, we see that regardless of the pre or post ovulatory phase, the thickness of the endometrium varies according to the age group.

The results from the correlation between endometrial thickness and BMI are shown in Figures 5 and 6.

It emerges from the analysis of Figures 5 and 6 that the value of the thickness of the endometrium increases with the BMI values between [15.20 [, [20.25 [and [25.30 [and decreased for women with BMI values above 30.

Figures 7 and 8 show the correlation results between the thickness of the endometrium and the weight of the woman.

Analysis of Figures 7 and 8 show that it has an association between the thickness of the endometrium and the weight of women during the pre- and post-ovulatory periods. 


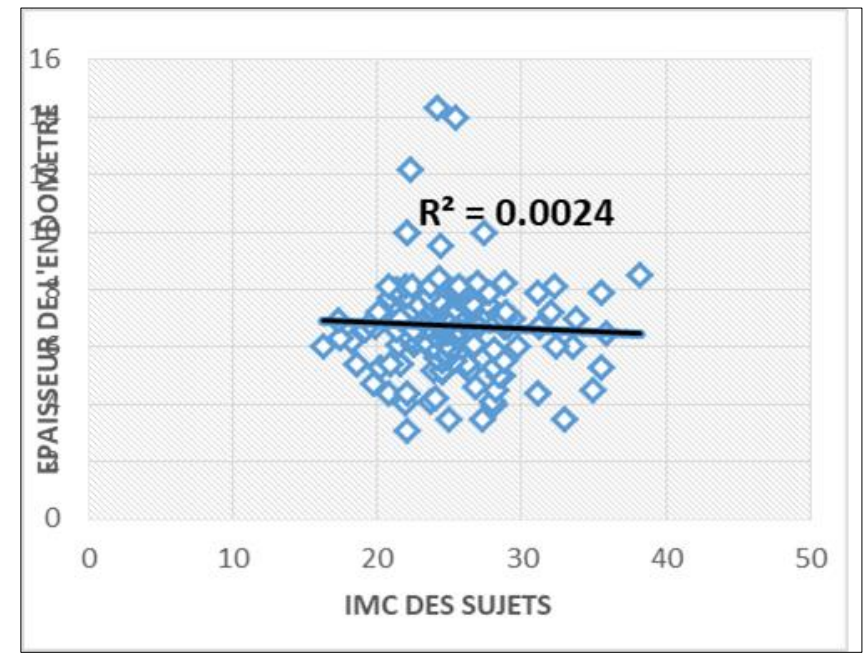

Figure 5 Endometrial thickness in phase

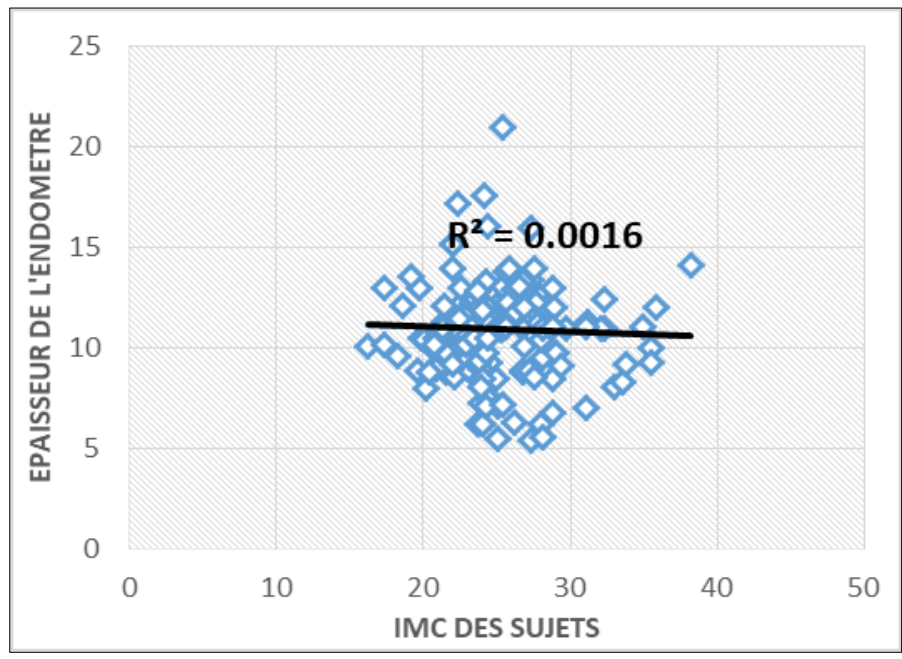

Figure 6 Endometrial thickness in phase pre-ovulatory and post-ovulatory BMI and BMI; (Source: Fieldwork, Komahoue, 2019)

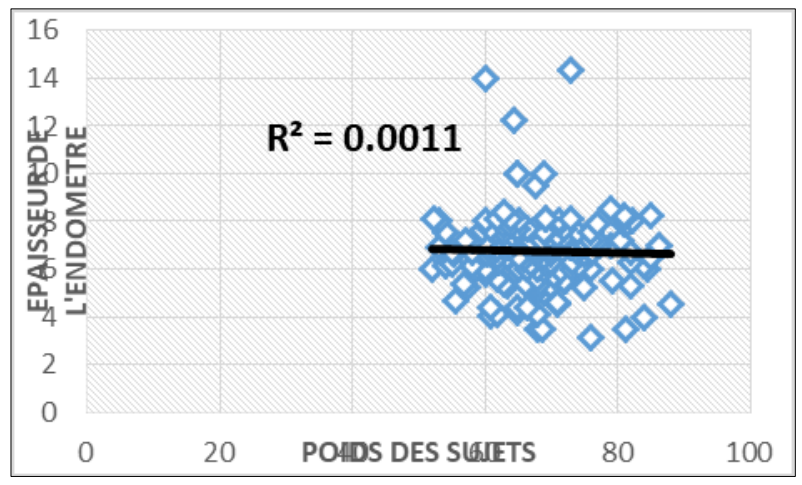

Figure 7 Endometrial thickness in phase

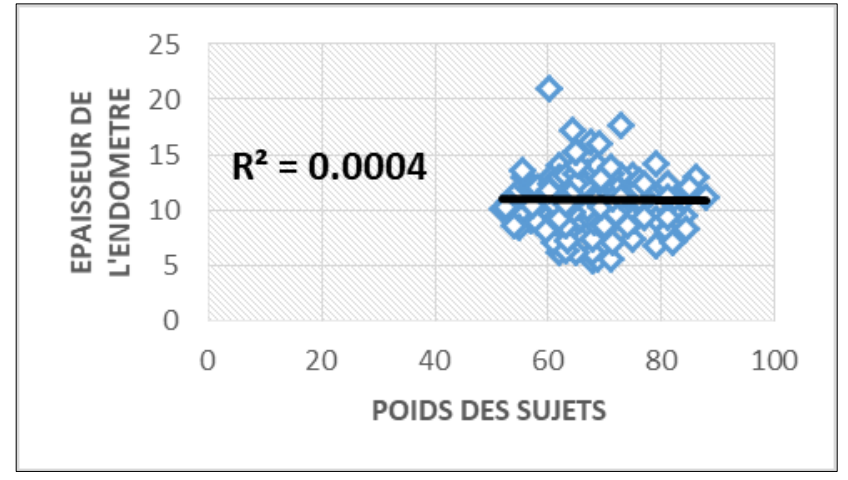

Figure 8 Endometrial thickness in phase preovulatory by weight postovulatory by weight; (Source: Fieldwork, Komahoue, 2019)

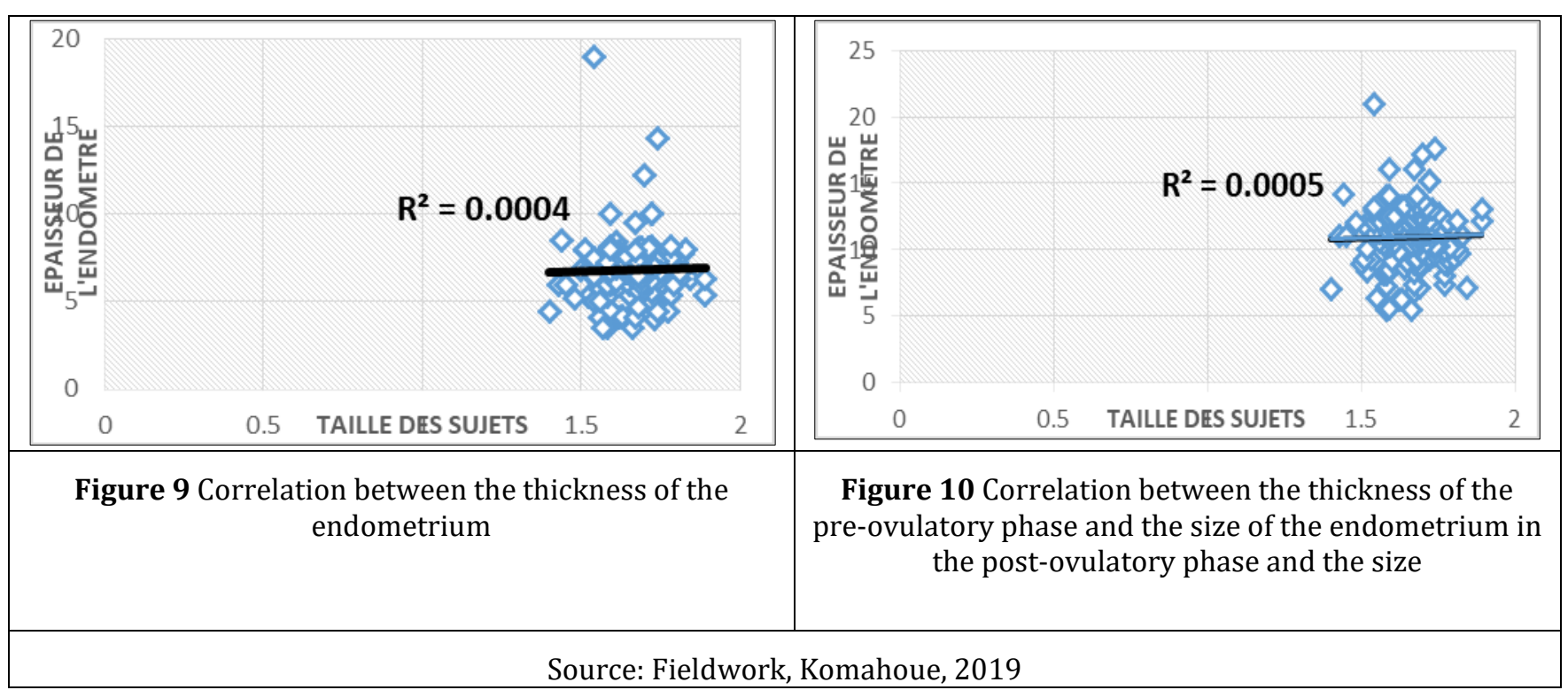


From the examination of Figures 9 and 10, it is concluded that there is a perfect correlation between the thickness of the endometrium and the height of women.

\subsection{Comparison test}

Table 5 Comparison test of the mean values of the thickness of the endometrium of women according to the phases of the menstrual cycle

\begin{tabular}{lcccc|}
\hline PHASES & $\mathbf{V}_{\text {moy }}$ & Variance & Eff & $\mathbf{p}$ \\
\hline Pré & 07.46 & 03.02 & 83 \\
\hline Post & 11.69 & 05.56 & 83 & 0.00 \\
\hline \multicolumn{5}{|c}{ Source: Fieldwork, Komahoue, 2019} \\
\hline
\end{tabular}

Analysis of Table $\mathrm{V}$ reveals that the $\mathrm{p}$ valued is less than 0.001 , which explains why there is a significant difference between the thickness of the endometrium and the menstrual cycle. So the thickness of a woman's endometrium varies depending on her regular or irregular menstrual cycle.

Table 6 Comparison test of the mean values of the thickness of the endometrium of women according to age groups

\begin{tabular}{ccccc|c|}
\hline AGES & PHASES & Vmoy & Variance & Eff & P \\
\hline \multirow{2}{*}[15,25]{} & Pré & 07.98 & 88.26 & 38 & \multirow{2}{*}{0.02639} \\
\cline { 2 - 5 } & Post & 11.96 & 41.29 & 38 & \\
\hline \multirow{2}{*}[25,50]{} & Pré & 07.28 & 27.67 & 138 & \multirow{2}{*}{0.000} \\
\cline { 2 - 5 } & Post & 11.73 & 87.91 & 138 & \\
\hline
\end{tabular}

Comparative analysis of endometrial thickness in the pre- and post-ovulatory phases showed a significant difference both on the total sample and in the two age groups [15, 25 [and [25, 50].

Table 7 Comparison test of the mean values of the thickness of the endometrium of women in the pre- and postovulation periods according to the BMI ranges

\begin{tabular}{|c|c|c|c|c|c|}
\hline IMC & PHASES & Vmoy & Variance & Eff & $\mathbf{P}$ \\
\hline \multirow{2}{*}[-;24,9]{} & Pré & 7.39 & 35.06 & 90 & \multirow{2}{*}{0.0002537} \\
\hline & Post & 7.54 & 132.14 & 90 & \\
\hline \multirow{2}{*}[24,9;+]{} & Pré & 12.48 & 52.89 & 76 & \multirow{2}{*}{0.0002072} \\
\hline & Post & 10.95 & 6.54 & 76 & \\
\hline
\end{tabular}

From the analysis of Table VII, the comparison test is statistically significant between the mean values of the thickness of the endometrium of women in the pre- and post-ovulatory periods according to the BMI values.

\section{Discussion}

Ultrasound is an important means of exploration which provides information on many pathologies and makes it possible to take measurements such as that of the endometrium. It is used in the present research to study the endometrial morphology of 166 women ranging in age from 15 to 40 years. According to the methodological approach adopted, all the women were examined only via the suprapubic route, unlike [6] (Flescher et al., 1986) and [7] (Lemercier, et al., 2000), according to which it is the endovaginal route that was recommended for a better exploration of the endometrium. Because according to these authors, during exploration, the probe is closer to the structure to be examined and provides more precision. This route was not used in this study for several reasons, the first reason being that the research was carried out in a rural environment where cultural and religious realities have a lot of impact on 
community life, therefore women do not. 'Don't like to expose their nudity, another thing is that some young people in the study sample still say they are virgins.

Of the 166 women recorded, the most represented age group was [25, 30 [, which explains why the sample is made up more of young women and it is in this type of population that endometrial activity is more dense. Compared to [8] (Kehila et al., 2010) who had done a study on the influence of the endometrium on embryo implantation in "in vitro" fertilization in a young population?

In the present study, the average BMI is $25.41 \pm 3.68 \mathrm{Kg} \mathrm{m} 2$, this result is comparable to that found by WHO in 2016 , which is $25.41 \mathrm{Kg} / \mathrm{m} 2$.

It also emerges from these results that $36.75 \%$ of women were overweight, which corroborates the results of [9] (Yessoufou et al. 2012) who found the same results among students of the National Medico-social Institute of Benin who were generally of childbearing age. Also, the diagnosis of the nutritional situation drawn up by the strategic plan for the development of food and nutrition shows respectively in 2001 and 2008 a BMI greater than or equal to $33.9 \%$ and $37 \%$ (overweight) was predominant among children. girls of childbearing age in all departments of Benin.

Regarding the nature of the cycle, 133 women had a regular cycle, ie a percentage of $80.12 \%$. This result is slightly higher than that of [10] (Tsuda et al., 2017) who found 70\%. This difference may be due to the origin (Japan) of the women who participated in this study or to the large number of participants, which is 849 women.

In relation to the search for an association link between the thickness of the endometrium during the pre and postovulatory periods and the anthropometric variables (age, height, weight and BMI) $(r=0.000)$ he did not no association link was observed, the same observation was made by [10](Tsuda et al., 2017). Contrary to this study, an association was noted between the thickness of the endometrium and the BMI by [11](Anita et al., 2004) who had carried out an endovaginal study on the thickness of the endometrium as a biomarker under estrogen. This difference can be explained by the route used and the effect of the estrogen used.

In addition, this study made it possible to bring out the minimum, average and maximum values of the thickness of the endometrium according to the different phases of the sexual cycle of women aged 15 to 40 whose endometrium has a normal echostructure.

Indeed, these values are respectively $\mathrm{Vm}=3.50 \mathrm{~mm}$, VMoy $=6.73 \pm 1.38 \mathrm{~mm}, \mathrm{VM}=10.00 \mathrm{~mm}$ during the pre-ovulatory phase, $\mathrm{Vm}=7.30 \mathrm{~mm}$, VMoy $=10.75 \pm 2.11 \mathrm{~mm}, \mathrm{VM}=16.00 \mathrm{~mm}$. Comparatively these values are substantially equal to those found by (Houenha et al 2012): $\mathrm{Vm}=4.2 \mathrm{~mm}, \mathrm{Vmoy}=9.59 \pm 2.14 \mathrm{~mm}, \mathrm{MV}=13 \mathrm{~mm}$ at the pre-ovulatory phase, $\mathrm{Vm}$ $=9 \mathrm{~mm}, \mathrm{Vmoy}=11.69 \pm 1.34 \mathrm{~mm}$ and $\mathrm{MV}=15.3 \mathrm{~mm}$ in the post-ovulatory phase.

The comparative analysis of the thickness of the endometrium in the pre and post-ovulatory phases showed a statistically significant difference both on the total sample and in the two age groups $[15,25$ [and $[25,50[(P=0.000)$. The same remark was made for the comparison between the thickness of the endometrium in the pre- and postovulatory phase according to the two BMI slices. Thus, the thickness of the endometrium varies between age groups and BMI ranges.

\section{Conclusion}

The physiology of the woman during the periods of her life is still a mystery even if many studies have partially provided information on the normal state of functioning of the female genital system and on the corollary pathologies. The present study initiated with the aim of also contributing to a better knowledge of the physiology of women has shown that the average thickness of the endometrium of women before the ovulation period is $6.73 \pm 1.38$ and $10.75 \pm 2.11$ after the ovulatory period. Endometrial and ovarian abnormalities were rare in this study. Factors such as age and BMI were significantly associated with changes in endometrial thickness in these women aged 15 to 40 . This work will serve as a basis for other more targeted studies on a large sample size with exploration by the two routes of suprapubic and endovaginal first to perfect these results.

However, it is important that additional studies take into account many more ultrasound and physiological parameters to control the factors that influence endometrial changes. These results will certainly allow a better ultrasound diagnosis of endometrial pathologies. 


\section{Compliance with ethical standards}

\section{Acknowledgments}

We thank everyone who contributed to the writing of this manuscript. In particular, we thank the women who agreed to participate in this research, we thank the director of the departmental hospital of Mono.

\section{Disclosure of conflict of interest}

The writing of this manuscript is without conflict of interest. Each of the authors contributed to the success of this manuscript.

\section{References}

[1] Traub ML, Van Arsdale A, Pal L, Jindal S, Santoro N. Endometrial thickness, Caucasian ethnicity, and age predict clinical pregnancy following fresh blastocyst embryo transfer: a retrospective cohort. Reproductive Biology and Endocrinology : RBE. 2009; 7: 33.

[2] Bernard P., Lecuru F. Darles C.. Use of ultrasonography as a first lineinvestigation of the uterus. Results of a prospective study. Genecol Obstet Biol Reprod. 1998: 27(2): 167-173

[3] Sher G, Herbert C, Maassarani G. Jacobs MH. Assessment of the late proliferative phase endometrium by ultrasonography in patients undergoing in-vitro fertilization and embryo transfer (IVF/ET). Human Reproduction. 1991; 6: 232-237.

[4] Dickey RP, Olar TT, Curole DN, Taylor SN, Rye PH. Endometrial pattern and thickness associated with pregnancy outcome after assisted reproduction technologies. Human Reproduction. 1992; 7: 418-421.

[5] Bergeron C. Histologie et pathologie de l'endomètre normal. 2006; 31-L-10.

[6] Flescher A, Kalameris G, Entman S. Sonography depiction of the endometrium during normal cycle. Ultrasound Med Biol. 1986; 12: 271-277.

[7] Lemercier E, Genevois A, Benozio M, Descargues G, Marpeau L. L'endomètre : quelle imagerie? 2000; 81: 18451855.

[8] Kehila M, Kebaili S, Bougmiza I, Meddeb S, Boughizane S, HediKhairi Ajina M. Influence de l'épaisseur de l'endomètre sur l'implatation embryonnaire en fecundation in vitro. 2010; 88: 928-932.

[9] Yessoufou GJD, E Attakpa, F BABA Moussa Hounhouigan, L Baba Moussa, A Sezan. Prevalence et role des lipids dans l'avènement de l'obésité au Bénin. 2012; 6(4): 1695-1702.

[10] Tsuda H, Ito YM, Todo Y, Iba T, Tasaka K, Sutou Y, alliés. Measurement of endometrial thickness in premenopausal women in office gynecology. Reproductive Medicine and Biology. 2017; 17: 29-35.

[11] Anita SYS, Modugno F, Lyndon MH, Martin J, Joel L. Weissfeld. Ultrasound Measurement of Endomrtrial Thickness as a Biomarker for Estrogen for Estrogen Exposure. 2004; 13: 9. 